\title{
Android interactive word game in mother tongue for early childhood learners
}

\author{
Rosie Jane P. Siosan ${ }^{1}$, Josephine R. Lavilla ${ }^{2}$, Ma. Asuncion Christine V. Dequilla ${ }^{3}$, Joel T. De Castro ${ }^{4}$ \\ ${ }^{1}$ School of Information and Communications Technology, West Visayas State University, Philippines \\ ${ }^{2}$ School of Industrial Technology, West Visayas State University, Philippines \\ ${ }^{3}$ College of Education, West Visayas State University, Philippines \\ ${ }^{4}$ College of Information and Communications Technology, West Visayas State University, Philippines
}

\begin{tabular}{l}
\hline \hline Article Info \\
\hline Article history: \\
Received Jan 15, 2021 \\
Revised Apr 4, 2021 \\
Accepted Apr 6, 2021 \\
\hline
\end{tabular}

Keywords:

Android application

Innovative tool

Interactive word game

Mother tongue

Spelling application

\begin{abstract}
As ownership of mobile devices increases, the trend in the use of information and communications technology (ICT) in education also advances. In line with the mandate of the department of education to develop interactive strategies, this study aimed to design, develop, and evaluate an android interactive word game in Mother Tongue on the level of acceptability of the system based on content, instructional quality, technical quality, presentation and organization, and accuracy and up-to-dateness to address the gap for interactive mobile learning. This study used developmental and quasiexperimental research. The first phase of the study used developmental research to design, develop, and evaluate the acceptability of the android word game. The second phase of the study used quasi-experimental to evaluate the effectiveness of the developed android word game on the pupils' academic performance in mother tongue. The evaluation of the information technology (IT) experts resulted to a very acceptable rating for the android interactive word game, which was observed to be effective based on the higher post-test mean score or higher mean score of the pupils in the spelling skills after their exposure to the android interactive word game.
\end{abstract}

This is an open access article under the CC BY-SA license.

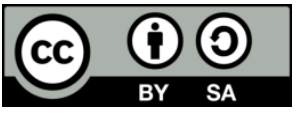

\section{Corresponding Author:}

Rosie Jane P. Siosan

School of Information and Communications Technology

West Visayas State University-Pototan Campus

Brgy. Cau-ayan Pototan, Iloilo, Philippines

Email: rosiejane.siosan@wvsu.edu.ph

\section{INTRODUCTION}

The conquest of learning is achieved through the knowledge of languages [1]. Language is one of the most important variables affecting education [2] and learners need to develop a strong foundation in their mother language before effectively learning additional languages. Using the vernacular or the child's first language is essential to learning as an intellectual ability [3], [4]. It makes learning how to read and write as well as how to acquire cognitive and reasoning skills easier for a child [5]-[7].

In 2009, the department of education (DepEd) provided directives for the inclusion of mother tongue-based multilingual education (MTBMLE) as a feature of the enhanced basic education program. Under DepEd Order No. 74 s. 2009, MTBMLE was institutionalized and implemented as a learning/subject area and as a medium of instruction. As a subject area, mother tongue education focuses on the development of speaking, reading, and writing from grades I to III while as a medium of instruction, mother tongue is used in all areas from Kinder to grade III except in teaching Filipino and English subjects. DepEd Order No. 32, s. 2012 further states the need to develop teaching strategies using unique features of the MTBMLE which shall 
include but not limited to "interactive strategies" and "use of manipulative games". The new curriculum created a domino effect on the need for instructional materials. These instructional materials do not only mean books, but also other interactive materials such as educational games for learners to enjoy schooling.

In a study entitled "Investigating Best Practice in MTBMLE in the Philippines" by Metila, et al. [8], it was found out that one of the challenges cited in the teaching of MTBMLE was the teacher's limited use of technology. Therefore, exploration on the potential of information and communications technology in materials development and production, and in the systematic and efficient conduct of materials validation was encouraged [8], [9]. On the other hand, the accessibility and availability of smartphones for children have increased significantly. Earlier studies conducted by "The State of the World's Children" 2017 has revealed that in the Philippines, the most common age for a child to own a mobile phone was 10 years old and that the Philippines has the highest proportion of children, at 76 percent, who use their mobile phones and tablets to access the Internet, play online games, and indulge in social media platforms.

Weakland [10], states that if students are provided student-centered learning activities, such as game-based learning through gamification, they may experience an improvement in motivation and rapid word recognition as they engage in a developmentally-appropriate learning process [11]-[13]. Moreover, if teachers used a gamified approach to teaching words, learning through play can be one of the most influential teaching strategies children may experience [14]-[17]. Gamified approaches using Android mobile phones in education were developed to capture the students' interest in learning languages. For example: "4 pics1word," [18] where users guess the word that relates to given pictures; "Edugame" [19], which provides children with a series of activities such as the construction of words and the recognition of letters; "LAUT-ABC" [20], which is an android-based app to teach children of the alphabet; and "Afaneen" [21], which is a mobile game that enhances skills in spelling in Arabic. Megawati and Sultoni [22], concluded that the use of Android-based educational games using computer assisted language learning (CALL) strongly influences the students' vocabulary mastery and their interest in learning English.

Considering the benefits of mobile technology and the mandate of the DepEd to develop interactive strategies and manipulative games in MTBMLE, this study designed, developed, and evaluated an Android interactive word game on the level of acceptability of the system based on the following criteria: i) content, ii) instructional quality, iii) technical quality, iv) presentation and organization, and v) accuracy and up-todateness of Information. Moreover, the effectiveness of the Android interactive word game as a supplementary pedagogical tool for early childhood learners was ascertained through a pre-test, pilot test, and post-test on pupils.

\section{RESEARCH METHOD}

This study used developmental [23] and quasi-experimental research, [24] and has undergone two phases: phase 1, the developmental research that included the analysis, design, development, and evaluation of the acceptability of the Android interactive word game, and phase 2, the quasi-experimental research used to evaluate the effectiveness of the Android interactive word game on the pupils' academic performance in mother tongue. This research employed both descriptive and inferential analysis. For the descriptive analysis, the statistical measures used were the mean and the standard deviation. For the inferential statistics, paired t-test was utilized.

\subsection{Research participants}

The participants of the study were sixty (60) grade III pupils from a public pilot school in the District of Iloilo, which were selected using the matched Pairs method. The same participants were used in the data gathering for the pre-test and post-test scores. Other respondents of this study included grade III MTBMLE teachers, grade III parents, IT experts, early childhood education teachers, child psychologists, and Hiligaynon experts. They were asked to answer the survey questionnaire and interviewed using focus group discussion (FGD) [25] to substantiate and verify the data gathered.

\subsection{Research instruments}

Research instruments are tools employed in a research study to collect, measure, and analyze data. To determine the acceptability and effectiveness of the mobile application, the following instruments were used in this study: Evaluation form for non-printed instructional materials and Pre-test and post-test. The Evaluation form for non-printed instructional materials was adapted from West Visayas State University System and was revised and undergone face and content validation. The researcher-made pre-test and posttest underwent validation and reliability testing to ensure the validity and reliability of the instruments before it was administered to the research participants. 


\subsubsection{Evaluation form for non-printed instructional materials}

The evaluation form for non-printed instructional materials made by the West Visayas State University System was adapted, modified, and validated. The word game was evaluated in the following aspects: i) content, ii) instructional quality, iii) technical quality, iv) presentation, and organization, and v) accuracy and up-to-dateness of Information. It has a four-point scale with the following codes and qualitative descriptions shown in Table 1.

Table 1. Four-point scale

\begin{tabular}{clcl}
\hline Numerical Value & \multicolumn{1}{c}{ Description Rating } & Mean Score & \multicolumn{1}{c}{ Description } \\
\hline 4 & Very Acceptable (VA) & $3.51-4.00$ & $\begin{array}{l}\text { If major aspects of the instructional tool are } \\
\text { adequately met and with an above-average standard } \\
\text { If major aspects of the instructional tool are met } \\
\text { and with minimum acceptability } \\
\text { If major aspects of the instructional tool are hardly } \\
\text { met and with below-average quality }\end{array}$ \\
1 & Acceptable (A) & $2.51-3.50$ & $\begin{array}{l}\text { If major aspects of the instructional tool are of } \\
\text { unacceptable quality }\end{array}$ \\
\hline
\end{tabular}

\subsubsection{Pre-test and post-test}

The researcher-made pre-test and post-test were based on the grade III curriculum and contained 10 items per category (animals, body parts, plants, and things) with a total of 40 items. The objective of the pre-test and post-test was to check for the spelling skills of the pupils. The questionnaire was subjected to face and content validity [26] before administration to the participants.

\subsubsection{Android interactive word game}

In designing a word game, the developmental tools, architectural design, and flow chart must be identified and developed first. The development tools used are the following: i) accelerator android studio for mobile application development, ii) sublime text for code editing for the website development, iii) Android SDK to enable the developer to create applications for the android platform, and iv) Adobe Photoshop to edit pictures used in the word game.

The architectural design in Figure 1 shows that the teacher is the administrator of the game [27], [28]. The "content authoring tool" allows the teacher to handle the server and manage the content of the word game such as categories, levels, pictures, spelling, and sounds. This feature provides the opportunity to include other words not found on the database. The web learning system uses the SQL server database management system (DBMS) as a repository of students' information and scores. The use case diagram shown in Figure 2 is used to demonstrate the ways that a user might interact with a system [29], [30].

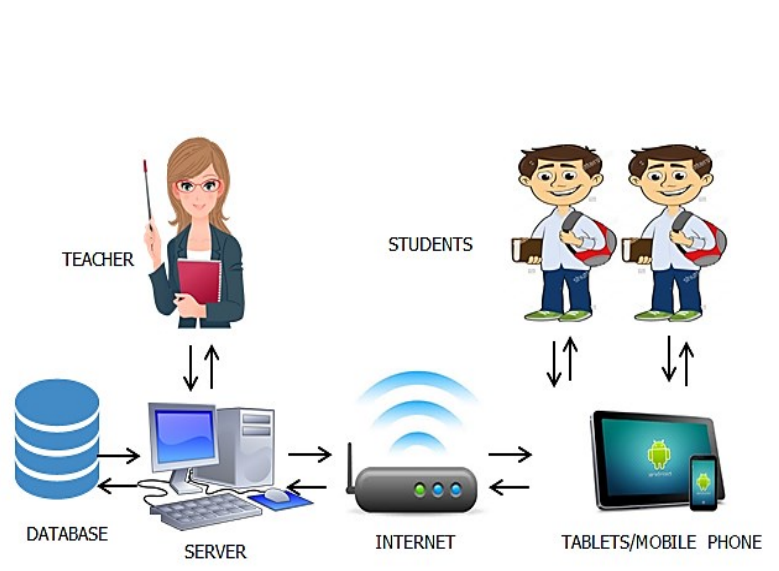

Figure 1. Architectural

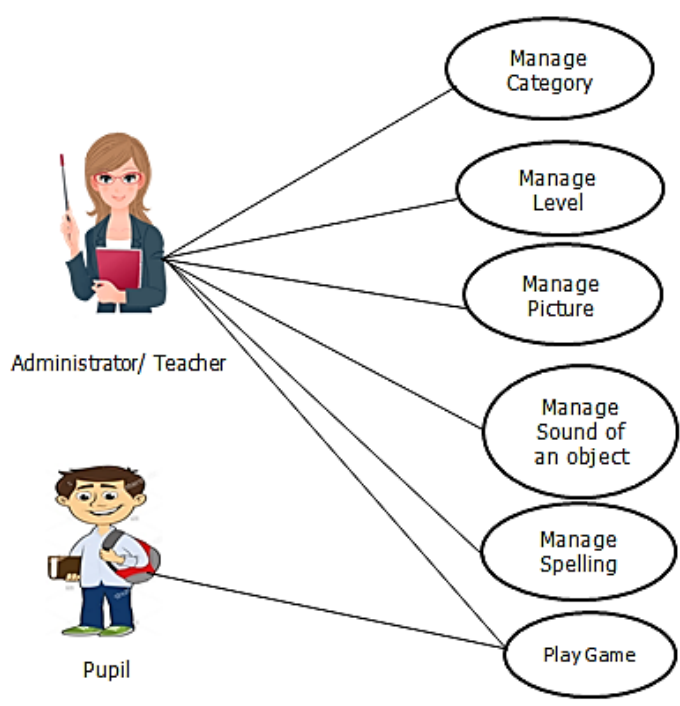

Figure 2. Use case 
The flowchart in Figure 3 shows the procedural details and the visual way of algorithm representation, it helps the programmer/tester in understanding the logic of the program. To play, the pupil needs to $\log$ in his name and select a teacher. He may choose from the categories of the game. Once a category is selected, the pupil starts with the easy level; every correct answer earns a star. After surpassing all the 10 items in each level, he may now proceed to the next level which is average and then difficult. The pupil may exit anytime he wishes.

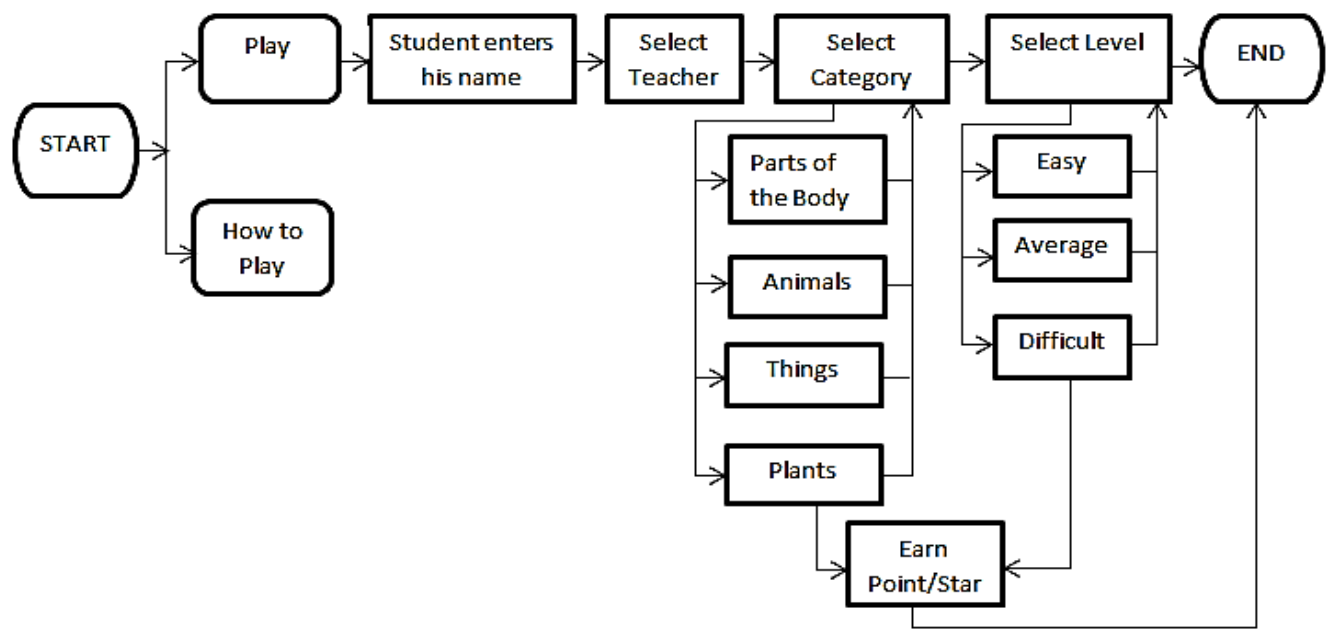

Figure 3. Flow chart of the word game

\subsection{Research procedures}

The methodology used in this study was the ADDIE instructional model design [31]. The stages in ADDIE were analysis, design, development, implementation, and evaluation. The framework of the study is shown in Figure 4.

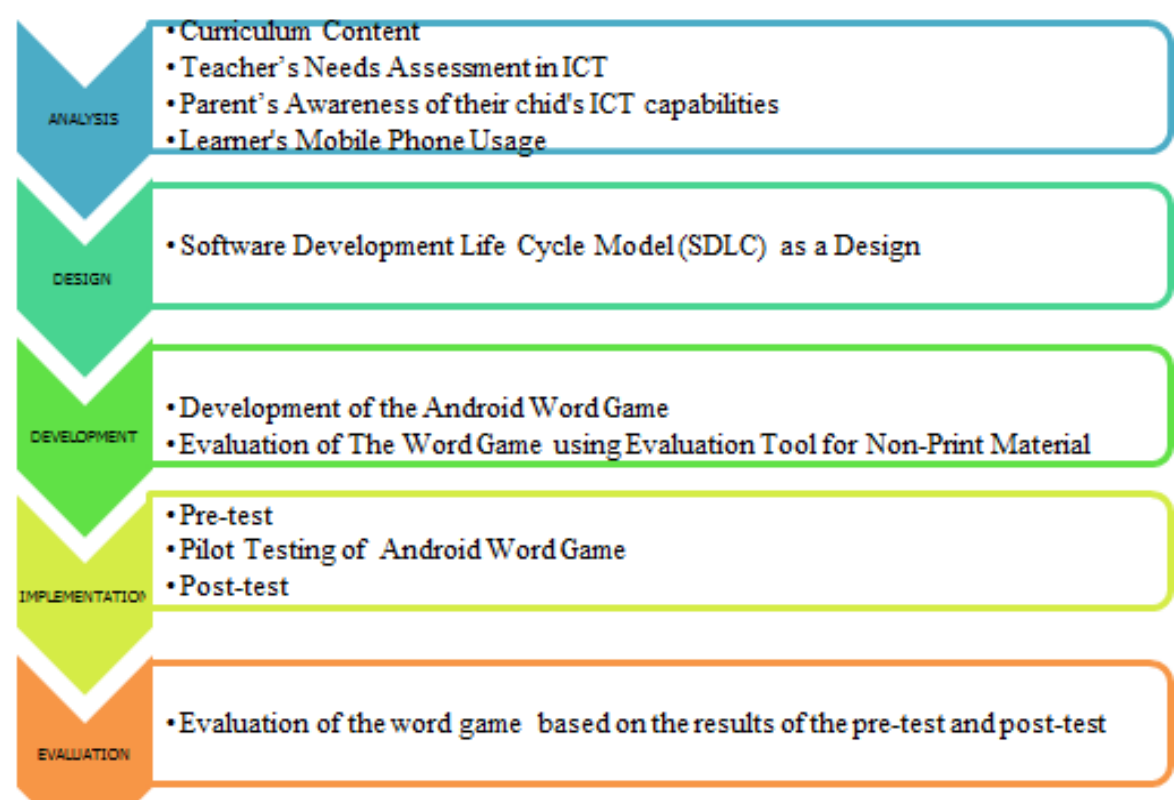

Figure 4. The Framework of the study 


\subsubsection{Phase I: Analysis, design, development, and evaluation of interactive word game}

In the analysis phase, the context of the curriculum was analyzed through the analysis of the curriculum content, ICT landscape, teacher's ICT needs assessment, parent's assessment of their child's use of digital devices, and learner's use of mobile phones. After a thorough analysis, an interactive android word game was designed and developed using systems development life cycle (SDLC) as a software development model [32]. The SDLC has the following stages: analysis, design, development, testing, deployment, and maintenance. The flow chart of the word game was then established to identify what to include in the input, process, and output of the word game. Also taken into consideration was the software to be used as well as the specifications of the android phone.

The word game was evaluated in terms of its content, instructional quality, technical quality, presentation and organization, accuracy, and up-to-datedness of information. Comments and suggestions were corroborated in the software. After all the testing, debugging, and iterations, the researcher was able to release a fully functional mobile application. It was tried out with the participants of the study.

\subsubsection{Phase II: Implementation and evaluation of the effectiveness of the interactive word game}

Ethical considerations such as voluntary participation and informed consent addressed to the school principal, teacher, parents, and students were taken into account before implementation. The participants of the study were the grade III pupils of a public pilot school in the district of Iloilo. One class with thirty (30) students was assigned to be the control group and the other class also with thirty (30) students was the experimental group. The experimental group participated in the playing of the interactive mobile learning and the control group via traditional (teacher-based) learning. During the implementation, external experts were invited as observers in the administration and pilot testing of the Android interactive word game application.

The implementation started by the giving of the pre-test to determine the spelling skills in MTBMLE of the pupils. To ensure that the two groups were comparable, a pre-test was given to the students in both sections. The researcher-made pre-test has 10 items per category (animals, body parts, plants, and things) with a total of 40 items. The instrument underwent reliability testing using Cronbach alpha with an alpha value of 0.96 . Since the value is above 0.7 , it means that the instrument is highly reliable [33].

During the pilot testing, the android interactive word game was deployed to an android device such as smartphones and tablets of the students. The teacher used gamification [34]-[36] in education by allowing students to play one category per day (starting with the easy level) then afterward the students were given a written spelling test. After the implementation, the students were interviewed through focus group discussion to provide feedback on the use of the word game. The study made four weeks between pre-test and post-test to avoid a threat to internal validity in an experimental study when participants may remember responses for post-test [37]. After the implementation of the interactive android word game, the teacher administered the post-test to check the effect of the android interactive word game on the pupils and to test for the significant difference in their spelling skills.

\subsection{Data analysis}

The data collected underwent statistical analysis with the use of the statistical package for social sciences (SPSS). This study utilized both descriptive and inferential analysis. For the descriptive analysis, the statistical measures used were the mean and the standard deviation. For the inferential statistics, paired t-test was used. Moreover, the effect size [38], [39] was used to test the magnitude of the experimental effect.

\section{RESULTS AND DISCUSSION}

\subsection{Instructional tool developed based on the software development process model}

The android interactive word game named "iTudlo" which means "to teach" in Hiligaynon was developed based on the analyzed parameters and SDLC model. The game includes images and words following DepEd Order No. 90 s. 2011 which gives the guidelines to create and reproduce materials that feature grade-level words and picture dictionaries. The word game targets the learning competencies in spelling. It was designed and developed as a supplementary tool in the teaching of the Mother Tongue subject for early childhood learners. Shown in Figure 5 is the user interface of the word game.

\subsection{Evaluation results of android interactive word game}

In general, the word game received a total mean score of 3.55 and a very acceptable recommendation from the jurors. In the five criteria of rating, in terms of word game content, the word game received a rating of very acceptable (Mean $=3.70, \mathrm{SD}=0.42$ ), instructional quality was very acceptable (Mean=3.53, SD=0.38), technical quality was acceptable (Mean=3.46, $\mathrm{SD}=0.47$ ), presentation and organization were very acceptable (Mean $=3.53, \mathrm{SD}=0.51$ ) and the accuracy and up-to-datedness of Information were very acceptable (Mean $=3.53, \mathrm{SD}=0.51$ ). The scores were reflected in Table 2 . 


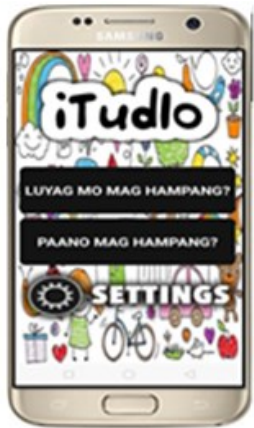

Welcome Screen

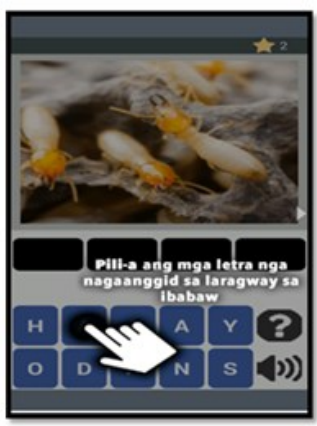

Tutorial Guide

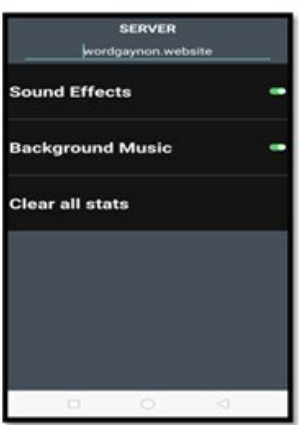

Settings

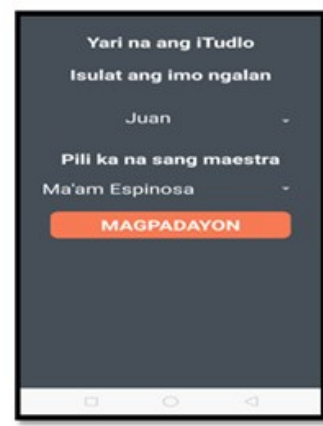

Log-in Page

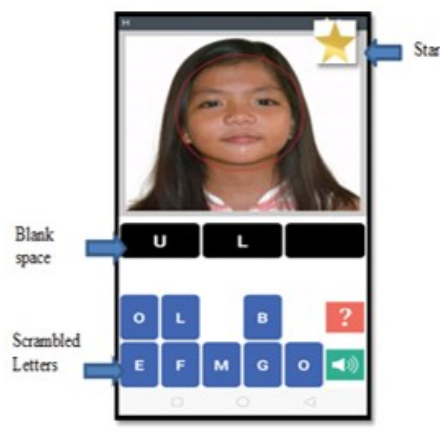

Sample Screen of Body Parts

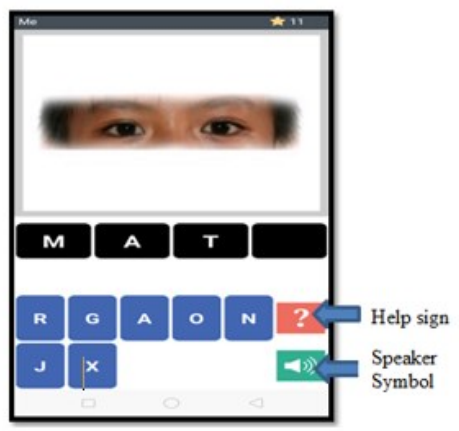

Help Options

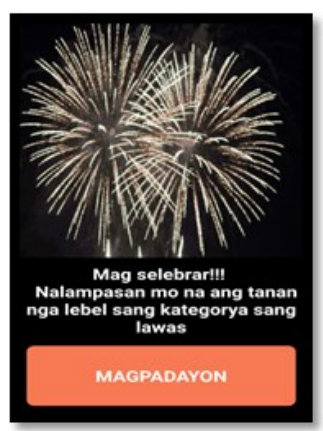

Game Rewards

Figure 5. Android interactive word game user interface

Table 2. Juror's rating of the word game

\begin{tabular}{lccl}
\hline \multicolumn{1}{c}{ Criteria } & SD & Mean & Descriptive Rating \\
\hline A. Content & 0.42 & 3.7 & Very Acceptable \\
B. Instructional Quality & 0.38 & 3.53 & Very Acceptable \\
C. Technical Quality & 0.47 & 3.46 & Acceptable \\
1. Presentation & 0.67 & 3.33 & Acceptable \\
2. Navigation / User Interface & 0.45 & 3.57 & Very Acceptable \\
3. Audio/ Music & 0.58 & 3.4 & Acceptable \\
4. Technical Requirement & 0.65 & 3.53 & Very Acceptable \\
5. Interactivity and Feedback & 0.51 & 3.47 & Acceptable \\
D. Presentation \& Organization & 0.51 & 3.53 & Very Acceptable \\
E. Accuracy \& Up-To-Datedness of Information & 0.51 & 3.53 & Very Acceptable \\
\hline
\end{tabular}

Note 3.51-4.00- "Very Acceptable," if major aspects of the instructional tool are adequately met and with an above-average standard; 2.51-3.50- "Acceptable," if major aspects of the instructional tool are met and with minimum acceptability 1.51-2.50- "Moderately Acceptable," if major aspects of the instructional tool are hardly met and with below-average quality; 1.00-1.50- "Barely Acceptable," if major aspects of the instructional tool are of unacceptable quality.

\subsection{Effect of the word game on the spelling skills of the pupils before and after the intervention}

The evaluation of the effect of the word game on the spelling skills of the pupils before and after the intervention results show that there was a significant difference in the level of spelling skills of the pupils before and after the intervention was introduced. This was supported by the results of higher mean score in the post-test after exposure to android interactive word game in all categories: a) body parts $(\mathrm{t}=-5.38$, $p=.000)$; b) animals $(\mathrm{t}=-12.47, p=.000)$; $)$ things $(\mathrm{t}=-8.72, p=.000)$; and $\mathrm{d})$ plant $(\mathrm{t}=-3.97, p=.000)$. The "Sig" or the p-value of 0.000 indicates that a significant difference was found in each of the categories since it is less than 0.05 which was the significance level that was used in this study.

This significance level of 0.05 was used since this is educational research. The lower and upper confidence level which appeared in the table is the lower and upper bound of the confidence interval of the mean difference. Moreover, the data indicate that the scores of the pupils for the experimental and controlled groups both have increased. However, the scores of the experimental group in the post-test were higher compared to the controlled group in all four categories of the exams. This evidence indicates that the spelling skills of the pupils have improved after interacting with the word game for some time. The results were in Table 3 . 
Table 3. The significant difference in the level of spelling skills of the pupils (experimental)

\begin{tabular}{|c|c|c|c|c|c|c|c|}
\hline \multirow{2}{*}{ Category } & \multirow{2}{*}{$n$} & \multirow{2}{*}{ Mean } & \multirow{2}{*}{ Mean Diff. } & \multirow{2}{*}{$t$-value } & \multirow{2}{*}{$\begin{array}{l}\text { Sig. or } \\
\text { p-value }\end{array}$} & \multicolumn{2}{|c|}{ Confidence Interval } \\
\hline & & & & & & Lower & Upper \\
\hline \multicolumn{8}{|c|}{ A. Parte sang Lawas (Parts of the Body) } \\
\hline Pre-test & 30 & 9.26 & 0.7018 & $5.38 *$ & 0 & -0.935 & -0.42 \\
\hline Post-test & 30 & 9.94 & & & & & \\
\hline \multicolumn{8}{|c|}{ B. Sapat (Animals) } \\
\hline Pre-test & 30 & 8.1 & 0.6768 & $12.47 *$ & 0 & -1.764 & -1.268 \\
\hline Post-test & 30 & 9.61 & & & & & \\
\hline \multicolumn{8}{|c|}{ C. Butang (Thing) } \\
\hline Pre-test & 30 & 8.58 & 0.7002 & $8.72 *$ & 0 & -1.354 & -8.399 \\
\hline Post-test & 30 & 9.68 & & & & & \\
\hline \multicolumn{8}{|c|}{ D. Tanum (Plant) } \\
\hline Pre-test & 30 & 9.42 & 0.7244 & $3.97 *$ & 0 & -0.782 & -0.25 \\
\hline Post-test & 30 & 9.94 & & & & & \\
\hline
\end{tabular}

\section{CONCLUSION}

The evaluation results of the android interactive word game with a total mean score of 3.55 equivalent to very acceptable indicate that major aspects of the instructional tool were adequately met and with an above-average standard. Furthermore, the results of the post-test indicated that the use of the Android Interactive word game as an intervention was effective in improving the spelling skills of the pupils in Hiligaynon. The results of the quasi-experimental study corroborated the effect of using a mixture of games, mobile learning, and ICT in the classroom in improving the spelling skills of the students. It was important however to emphasize that the effectiveness of a spelling tool in the form of a word game was also dependent upon learner's attitudes and motivation; therefore, keeping up motivation and interest was important for any subject that learners need to master. Moreover, the teachers' willingness to embrace new approaches in teaching plays a big role to facilitate learning. For future work, the research team intends to upgrade the android word game by including other mother tongue languages and to create a game for the IOS platform to widen utilization. Lastly, it is recommended to present the interactive word game to government agencies and private companies for mass utilization and production.

\section{ACKNOWLEDGEMENTS}

The research team would like to extend their gratitude to West Visayas State University-Main Campus, West Visayas State University-Pototan Campus, and Pototan Pilot Elementary School for the constant support in the successful conduct of this study. Likewise, our heartfelt thanks to the whole WVSU Community, our family, relatives, and friends, and to those who were not mentioned and acknowledged but contributed so much in the completion of this research, thank you so much for your prayers and encouraging words. To God be the highest glory.

\section{REFERENCES}

[1] J. S. Lee, "Informal digital learning of English and second language vocabulary outcomes: Can quantity conquer quality?," British Journal of Educational Technology, vol. 50, no. 2, pp. 767-778, 2019, doi: 10.1111/bjet.12599.

[2] J. P. J. M. Smits, A. H. M. Huisman, and K. Kruijff, "Home language and education in the developing world," United Nations Educational, Scientific and Cultural Organization, 2008.

[3] R. Noormohamadi, "Mother Tongue, a Necessary Step to Intellectual Development," Journal of Pan-Pacific Association of Applied Linguistics, vol. 12, no. 2, pp. 25-36, 2008.

[4] A. V. Awopetu, "Impact of mother tongue on children's learning abilities in early childhood classroom," ProcediaSocial and Behavioral Sciences, vol. 233, 58-63, 2016, doi: 10.1016/j.sbspro.2016.10.131.

[5] C. Benson, "The importance of mother tongue-based schooling for educational quality," Commissioned Study for EFA Global Monitoring Report, p. 24, 2005.

[6] E. R. Fernando, "Effect of Mother Tongue-Based Education (Waray-Waray) in Teaching Mathematics Subjects Among Elementary Grade Pupils," International Journal of Linguistics, Literature, and Translation, vol. 3, no. 7, 23-29, 2020, doi: 10.32996/ijllt.

[7] S. Z. M. Abaton-Abantas and A. T. Untao, "Mother Tongue-Based Reading Materials for Grade III Pupils: A Proposal," Researchers World, vol. 11, no. 1, pp. 27-36, 2020, doi: 10.18843/rwjasc/v11i1/04.

[8] R. Metila, L. Pradilla, and A. Williams, "Investigating best practice in MTB-MLE in the Philippines-Phase 2 progress report: patterns of challenges and strategies in the implementation of mother tongue as the medium of instruction in the early years: a nationwide study," Assessment Curriculum and Technology Research Centre (ACTRC), The University of Melbourne, 2016. 
[9] A. Williams, R. Metila, L. Pradilla, and M. Digo, "Investigating best practice in MTB-MLE in the PhilippinesPhase 1 Progress Report: strategies and challenges in MTB-MLE implementation in the early years," Assessment Curriculum and Technology Research Centre (ACTRC), The University of Melbourne, 2014.

[10] N. L. Weakland, "Implementation of educational games-based instruction for improving sight word recognition," Doctoral dissertation, Bowling Green State University, USA, 2013.

[11] A. N. Alshammari, "A quantitative study of the impact of immersive game-based learning on enhancing vocabulary instruction and acquisition for English language learners," Thesis, Department of Instructional Design and Technology, Western Illinois University, USA, 2013.

[12] B. Snow, "The potential for game-based learning to improve outcomes for nontraditional students," Muzzy Lane Software Report, funding from Bill and Melinda Gates Foundation, 2016.

[13] P. Ladley, "Games Based Learning Theory and Practice," ICT in Practice. [Online]. Available: http://www.ictinpractice.com/games-based-learning-theory-and-practice-by-paul-ladley/

[14] B. Gros, "Digital games in education: The design of games-based learning environments," Journal of research on technology in education, vol.40, no. 1, pp. 23-38, 2007, doi: 10.1080/15391523.2007.10782494.

[15] K. Squire, "Video games in education, " International. Journal Intell. Games \& Simulation, vol. 2, no. 1, pp. 49-62, 2003.

[16] K. Squire and H. Jenkins, "Harnessing the power of games in education," Insight, vol. 3, no. 1, pp. 5-33, 2003.

[17] M. H. Al-Tarawneh, "The effectiveness of educational games on scientific concepts acquisition in first-grade students in science," Journal of Education and Practice, vol. 7, no. 3, pp. 31-37, 2016.

[18] N. Micallef and N. A. Arachchilage, "A Gamified Approach to Improve Users' Memorability of Fall-back Authentication," ArXiv, abs/1707.08073, 2017

[19] B. Hssina, et.al. "Edugame an Android game for teaching children," International Journal of Innovation and Applied Studies, vol. 9, no. 4, pp. 1531-1540, 2014

[20] A. G. Salman and C. Antonius, "Interactive educational game, an android mobile app for children learning alphabets," Library Hi Tech News, vol. 34, no. 5, pp. 20-22, 2017, doi: 10.1108/LHTN-04-2017-0021, 2017.

[21] M. S. Al-Razgan, "Afaneen: The Design and Evaluation of an Interactive Mobile Game to Enhance Arabic Spelling," Journal of Universal Computer Science, vol. 23, no. 12, pp. 1172-1199, 2017, doi: 10.3217/jucs-023-12-1172.

[22] F. Megawati and S. Sultoni, "Android Based Educational Game in Indonesian TEYL," in The 63rd International TEFLIN Conference 2016, 8-10 September 2016, Universitas PGRI Adi Buana (UNIPA), Surabaya, 2016, pp. 662-668, doi: 10.6084/m9.figshare.4559218.v3.

[23] M. C. Castro, "Teaching Phonemic Awareness to Preschool Children through Multimedia Instructional Materials," Thesis, Department Educational Management, Baliuag University, Philippines, 2019.

[24] O. A. Nanda and Insih Wilujeng, "The Effectiveness of Android-assisted Optical Devices Learning to Improve Students' Conceptual Understanding," Jurnal Penelitian dan Pembelajaran IPA, vol. 4, no. 2, pp. 105-115, 2018, doi: $10.30870 /$ jppi.v4i2.4038.

[25] O. Nyumba, K. Wilson, C. Derrick, and N. Mukherjee, "The use of focus group discussion methodology: Insights from two decades of application in conservation," Methods in Ecology and Evolution, vol. 9, no. 1, pp. 20-32, 2018, doi: $10.1111 / 2041-210 X .12860$.

[26] H. Taherdoost, "Validity and reliability of the research instrument; how to test the validation of a questionnaire/survey in a research," SSRN Electronic Journal, vol. 5, no. 3, pp. 28-36, 2016, doi: $10.2139 /$ ssrn.3205040.

[27] R. Rogers, J. Lombardo, Z. Mednieks, and B. Meike, Android application development: Programming with the Google SDK, Massachusetts, USA: O'Reilly Media, 2009.

[28] M. Roccetti, et al., "On the design of a word game to enhance Italian language learning," 2016 International Conference on Computing, Networking and Communications (ICNC), 2016, pp. 1-5, doi: 10.1109/ICCNC.2016.7440546.

[29] I. Jacobson, I. Spence, and B. Kerr, "Use-case 2.0: The hub of software development," Queue, vol. 14, no. 1, pp. 94-123., 2016, doi: 10.1145/2898442.2912151.

[30] D. Kulak, and E. Guiney, Use cases: requirements in context, Boston, Massachusetts, USA: Addison-Wesley Professional, 2012.

[31] M. S. Muslimin, N. M. Nordin, A. Z. Mansor, and M. Md. Yunus, "The design and development of MobiEko: a mobile educational app for microeconomics module," Malaysian Journal of Learning and Instruction, pp. 221-255, 2017, doi: 10.32890/mjli.2017.7804.

[32] M. M. Kirmani, "Agile methods for mobile application development: A comparative analysis," International Journal of Advanced Research in Computer Science, vol. 8, no. 5, pp. 1200-1205, 2017, doi: 10.26483/ijarcs.v8i5.3664.

[33] K. S. Taber, "The use of Cronbach's alpha when developing and reporting research instruments in science education," Research in Science Education, vol. 48, no. 6, pp. 1273-1296, 2018, doi: 10.1007/s11165-016-9602-2.

[34] D. B. Appiah, "Gamification in education: improving elementary mathematics through engagement in hybrid learning in the classroom" Thesis, Department of General Art Studies, Kwame Nkrumah University of Science and Technology, Kumasi, Ashanti Region, Ghana, 2015.

[35] M. Hall, "What is gamification and why use it in teaching" The Innoavtive Instructor Blog, Johns Hopkins University, May 2014. [Online]. Available: https://ii.library.jhu.edu/2014/05/13/what-is-gamification-and-why-use-it-in-teaching/

[36] B. Kurshan,"The Intersection of Learning and Fun: Gamification in Education," Forbes Magazine News Article, Feb. 2016. [Online]. Available: https://www.forbes.com/sites/barbarakurshan/2016/02/11/the-intersection-oflearning-and-fun-gamification-in-education/?sh=379621689c19

[37] L. Cohen, L. Manion, and K. Morrison, "The nature of inquiry: setting the field," in Research methods in education, London, UK: Routledge, 2013, pp. 27-54. 
[38] R. Rosenthal, "Parametric measures of effect size," The handbook of research synthesis, vol. 621, no. 2, pp. 231-244, 1994.

[39] W. Thalheimer and S. Cook, "How to calculate effect sizes from published research: A simplified methodology," Work-Learning Research, vol. 1, pp. 1-9, 2002.

\section{BIOGRAPHIES OF AUTHORS}
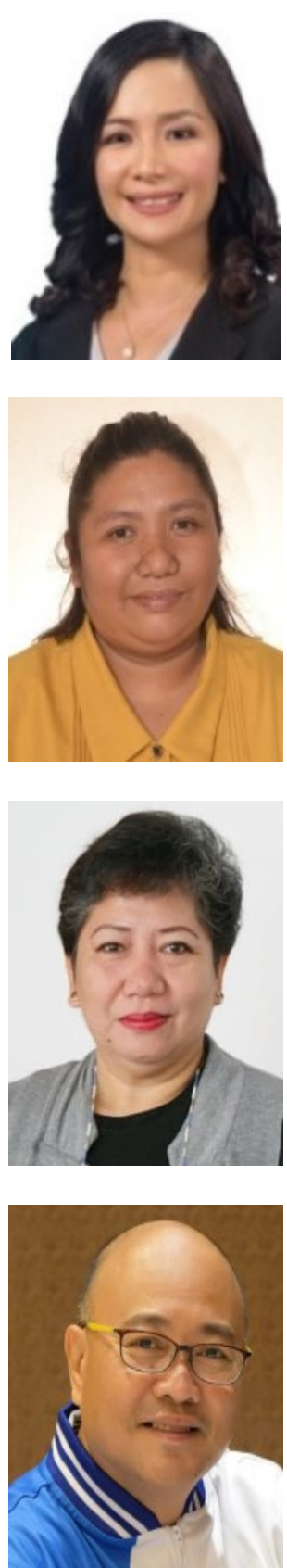

Dr. Rosie Jane P. Siosan is an Associate Professor at West Visayas State University-Pototan Campus, Philippines. She is a graduate of Doctor of Philosophy in Education major in Curriculum Development. Her areas of research interests include Teaching and Learning, Information and Communications Technology, Curriculum Development, and Electronics and Communications Engineering. Email address: rosiejane.siosan@wvsu.edu.ph

Dr. Josephine R. Lavilla is a Doctor of Philosophy major in Educational Management. She is a Registered Electrical Engineer and at the same time a licensed professional teacher. Her areas of research focus on Teaching and Learning, Statistics, Mathematics, Environment, and Electrical Engineering. Email address: josephine.lavilla@wvsu.edu.ph

Dr. Ma. Asuncion Christine V. Dequilla is the Vice President for Academic Affairs and a professor at West Visayas State University, Philippines. She handles professional education and language teaching subjects together with instructional technology courses in the graduate and undergraduate programs. Her research interests include bilingual education, psycholinguistics, discourse analysis, linguistics, and instructional technology as it cuts across disciplines. She obtained a Ph.D. in applied linguistics from La Salle University and a grant from the Australian prizes in digital literacy. Email address: mac.dequilla@wvsu.edu.ph

Dr. Joel T. De Castro is a Doctor of Industrial Technology and a professor at West Visayas State University, Philippines. He has occupied various administrative posts and currently he is the Head of Green Technology Business Incubation at West Visayas State University. A known innovator and researcher in the field of Distributed Systems and IT Security, his research interest lies in the area of IT security and Protection, Distributed Systems, Machine Intelligence, and SMS Systems. Email address: decastro_joel@wvsu.edu.ph 